\title{
Long-term dynamics of death rates of emphysema, asthma, and pneumonia and improving air quality
}

This article was published in the following Dove Press journal:

International Journal of COPD

16 June 2014

Number of times this article has been viewed

\author{
Julia Kravchenko' \\ Igor Akushevich ${ }^{2}$ \\ Amy P Abernethy ${ }^{3}$ \\ Sheila Holman ${ }^{4}$ \\ William G Ross $\mathrm{Jr}^{5}$ \\ H Kim Lyerly ${ }^{1,6}$ \\ 'Department of Surgery, ${ }^{2}$ Center for \\ Population Health and Aging, ${ }^{3}$ Duke \\ Clinical Research Institute, Duke \\ University Medical Center, Duke \\ University, Durham, ${ }^{4}$ Division of Air \\ Quality, North Carolina Department \\ of Environment and Natural \\ Resources, Raleigh, ${ }^{5}$ Nicholas School \\ of the Environment, ${ }^{6}$ Department of \\ Pathology, Duke University Medical \\ Center, Duke University, Durham, \\ NC, USA
}

Background: The respiratory tract is a major target of exposure to air pollutants, and respiratory diseases are associated with both short- and long-term exposures. We hypothesized that improved air quality in North Carolina was associated with reduced rates of death from respiratory diseases in local populations.

Materials and methods: We analyzed the trends of emphysema, asthma, and pneumonia mortality and changes of the levels of ozone, sulfur dioxide $\left(\mathrm{SO}_{2}\right)$, nitrogen dioxide $\left(\mathrm{NO}_{2}\right)$, carbon monoxide (CO), and particulate matters $\left(\mathrm{PM}_{2.5}\right.$ and $\left.\mathrm{PM}_{10}\right)$ using monthly data measurements from air-monitoring stations in North Carolina in 1993-2010. The log-linear model was used to evaluate associations between air-pollutant levels and age-adjusted death rates (per 100,000 of population) calculated for 5-year age-groups and for standard 2000 North Carolina population. The studied associations were adjusted by age group-specific smoking prevalence and seasonal fluctuations of disease-specific respiratory deaths.

Results: Decline in emphysema deaths was associated with decreasing levels of $\mathrm{SO}_{2}$ and $\mathrm{CO}$ in the air, decline in asthma deaths-with lower $\mathrm{SO}_{2}, \mathrm{CO}$, and $\mathrm{PM}_{10}$ levels, and decline in pneumonia deaths-with lower levels of $\mathrm{SO}_{2}$. Sensitivity analyses were performed to study potential effects of the change from International Classification of Diseases (ICD)-9 to ICD-10 codes, the effects of air pollutants on mortality during summer and winter, the impact of approach when only the underlying causes of deaths were used, and when mortality and air-quality data were analyzed on the county level. In each case, the results of sensitivity analyses demonstrated stability. The importance of analysis of pneumonia as an underlying cause of death was also highlighted.

Conclusion: Significant associations were observed between decreasing death rates of emphysema, asthma, and pneumonia and decreases in levels of ambient air pollutants in North Carolina.

Keywords: chronic obstructive pulmonary disease, sulfur dioxide, carbon monoxide, nitrogen dioxide, particulate matter

\section{Introduction}

Air pollution has a deleterious impact on human health, ${ }^{1-6}$ with global outdoor air pollutants estimated to account for approximately $1.4 \%$ of total mortality and $2 \%$ of all cardiopulmonary mortality. ${ }^{7}$ Both ambient particles ${ }^{4,8,9}$ and such gases as nitrogen dioxide $\left(\mathrm{NO}_{2}\right)$, ozone $\left(\mathrm{O}_{3}\right)$, and carbon monoxide $(\mathrm{CO})$ have been shown to increase total, cardiovascular, and respiratory (predominantly due to lung cancer and chronic obstructive pulmonary disease [COPD]) mortality and morbidity. ${ }^{3,10,11}$ While the impact on any individual's risk of death has been thought to be relatively modest per se, the overall impact of air pollution on the health of an exposed population makes it a major public health concern. ${ }^{12}$
Correspondence: Julia Kravchenko Department of Surgery, DUMC 3850 , Duke University Medical Center, Duke University, Durham, NC 27710, USA

Tel + I 9196686809

$\mathrm{Fax}+19196817970$

Email julia.krauchanka@duke.edu 
While more studies on short-term impacts of changes of air quality are available (such as the legislated traffic holidays during the 1996 Atlanta Olympic Games ${ }^{13}$ and the 2008 Beijing Olympic Games ${ }^{14}$ ), less is known about the long-term effects of changing air quality on the health of exposed populations. For example, a ban on heating-coal sales in Dublin was thought to be associated with both reduced pollution from airborne particulate matters (PMs) and $5.7 \%$ reduction in all-cause, $15.5 \%$ reduction in respiratory, and $10.3 \%$ reduction in cardiovascular mortality. ${ }^{15}$ However, these results were considered inconclusive, due to the complexity and expense of evaluating the health effects of air pollution on populations. ${ }^{16,17}$ Since the 1990s, a variety of acts, standards, and requirements in the US have been adopted to improve air quality. For example, increasingly stringent national gasoline and automotive engine requirements have been applied, resulting in a decrease of $\mathrm{CO}, \mathrm{NO}_{\mathrm{x}}$, $\mathrm{PM}$, and volatile organic compounds in the air. At the state level, North Carolina in 1992 entered into the Southern Appalachian Mountains Initiative, leading to the development of the Clean Smokestacks Act ${ }^{18}$ to mandate reduced emissions from coal-fired power plants. ${ }^{19}$

While few studies have analyzed the associations of both air quality and health over a long period, and they were typically limited to analysis of a specific air pollutant or a couple of pollutants, we were able to study longitudinally a number of air contaminants, including both PMs and noxious gases. In addition, we analyzed both air quality and health outcomes over almost two decades (1993-2010). Because respiratory morbidity and mortality are affected by changes in air quality, ${ }^{20-22}$ we evaluated the associations between the changes of the levels of $\mathrm{PM}_{10}$ and $\mathrm{PM}_{2.5}$, ozone, $\mathrm{CO}, \mathrm{NO}_{2}$, and $\mathrm{SO}_{2}$ in the air and death rates of emphysema, asthma, and pneumonia.

\section{Materials and methods Data}

We analyzed mortality rates for emphysema (International Classification of Diseases [ICD]-9 code 492, ICD-10 code J43), asthma (ICD-9 code 493, ICD-10 codes J45, J46), and pneumonia (ICD-9 codes 480.0, 480.1, 480.2, 480.9, 485, 486, 487.0, 487.1, ICD-10 codes J11.00, J11.1, J12.0, J12.1, J12.2, J12.9, J18.0, J18.9) in North Carolina from 1983 to 2010 using the data from the Vital Statistics National Center for Health Statistics Multiple Cause of Death dataset. We started the mortality analysis with the data from 1983, but could only analyze air quality when monitoring data were available, ie, 1993-2010. The mortality data enabled an analysis of a longer period of death-rate dynamics, thus allowing to observe the dynamics of disease-specific mortality before the measured reduction in particulate and gaseous emissions in North Carolina. Age-adjusted death rates (per 100,000 of population) were calculated using 5-year age-groups and standard 2000 North Carolina population. The data on population were provided by the Surveillance Epidemiology and End Results Registry (SEER) at http://www. seer.cancer.gov/popdata/download.html.

Data on concentrations of $\mathrm{PM}_{2.5}\left(\mu \mathrm{g} / \mathrm{m}^{3}\right), \mathrm{PM}_{10}\left(\mu \mathrm{g} / \mathrm{m}^{3}\right)$, ozone (ppb), $\mathrm{CO}$ (ppb), $\mathrm{NO}_{2}(\mathrm{ppb})$, and $\mathrm{SO}_{2}(\mathrm{ppb})$ in the air in 1993-2010 were obtained from the US Environmental Protection Agency (EPA) (http://www.epa.gov/ttn/airs/airsaqs/detaildata/downloadaqsdata.htm). We used the averaged month-specific concentrations of air pollutants for North Carolina to further analyze them for associations with the dynamics of cause-specific monthly mortality in the state. A two-stage averaging procedure was used to avoid heterogeneity in the numbers of measurements made in certain days of the month: first, we calculated the day-specific means, and then these values were averaged, resulting in month-specific means. Negative values were excluded, and measurements with various units were converted to $\mu \mathrm{g} / \mathrm{m}^{3}$ for $\mathrm{PM}_{2.5}$ and $\mathrm{PM}_{10}$, and to ppb for ozone, $\mathrm{CO}, \mathrm{NO}_{2}$, and $\mathrm{SO}_{2}$. Since the data on air pollutants represented different methods of registration during different durations of sample collection (ie, the length of time used to acquire a sample measurement), an auxiliary analysis was performed to check whether the specific method could be considered as an outlier and therefore excluded from the analyses.

Also, data on the prevalence of tobacco use for 1995-2010 were obtained from the Centers for Disease Control and Prevention Behavioral Risk Factor Surveillance System survey for age-groups $18-24,25-34,35-44,45-54,55-64$, and $65+$ years (http://www.cdc.gov/brfss).

\section{Ethics statement}

The data used in this study have no individual identifiable information. No specific procedures were required for deidentification of the records. All data analyses were designed and performed in accordance with the ethical standards of the committee on human experimentation and with the Helsinki Declaration (1975, revised in 1983), and were approved by the Duke University Health System Institutional Review Board.

\section{Methods}

Trends of cause-specific death rates and of levels of air contaminants were analyzed for correlations. Adjustment by 
smoking prevalence and seasonal fluctuations in respiratory deaths (for monthly death rates of emphysema, asthma, and pneumonia) were included in a log-linear model that was used to evaluate the associations between the level of each studied air pollutant and the death rates, as follows:

$$
\log (r)=u+\beta_{1} c+\beta_{2} s+\sum_{\mathrm{m}=1}^{11} \mu_{\mathrm{m}} I_{\mathrm{m}}+\mathcal{\varepsilon},
$$

where $u$ was the intercept, $\beta_{1}$ represented the effect of each studied air pollutant depending on its concentration (denoted by c) measured in its units (as described in the Data section), $\beta_{2}$ represented the effect of smoking prevalence (denoted by $s$ ), $\mu_{\mathrm{m}}$ represented the effects of 11 months (January to November for each year) in respect of December $\left(I_{\mathrm{m}}\right.$ is the month indicator), and $\varepsilon$ stood for random residuals. Note that if the air-pollutant concentration changes by one unit of its measured level in the air, the rate $r$ changes by the factor of $\exp \left(\beta_{1}\right)$. For multiple comparisons, the Bonferroni correction was applied.

\section{Sensitivity analysis}

The potential effect of ICD code changes (from ICD-9 to ICD-10), the seasonal fluctuation of air pollutants and mortality during summer and winter, and the analysis validity when only the underlying causes of deaths contributed to the cause-specific death rates were tested. In addition, sensitivity analysis was performed for county-level data on respiratory mortality and air-pollutant levels. Only counties for which the data on air quality were directly measured by monitoring stations were included in the analysis: 37 counties for ozone measurements, 11 counties for $\mathrm{NO}_{2}, 22$ counties for $\mathrm{SO}_{2}, 16$ counties for $\mathrm{CO}$, and 37 counties for $\mathrm{PM}_{2.5}$ and $\mathrm{PM}_{10}$ measurements. As in the main analysis, dynamics of smoking prevalence (on state level) and seasonal fluctuations in respiratory mortality were used for adjustments of the results.

\section{Results}

We analyzed up to 180 month-specific measurements of each of the studied air pollutants recorded at multiple monitoring sites in North Carolina (see Table 1 for detailed air pollutantspecific information). We found air quality in North Carolina gradually improving over time, primarily due to decreasing $\mathrm{PM}_{10}, \mathrm{NO}_{2}$, and $\mathrm{CO}$ levels. These decreases became more pronounced from 2002 (see Figure 1; note that individual pollutants were placed onto a single graph by utilizing the arbitrary units to enable a collective visualization of the trends). The following seasonal fluctuations of pollutants levels were observed (Figure 2): levels of ozone, $\mathrm{PM}_{2.5}$, and
Table I Measurements of air pollutants used in the study, 1993-2010

\begin{tabular}{lll}
\hline Air pollutant & $\begin{array}{l}\text { Number of } \\
\text { monitored sites }\end{array}$ & $\begin{array}{l}\text { Number of month- } \\
\text { specific measurements }\end{array}$ \\
\hline Ozone & 69 & 148 \\
Nitrogen dioxide & 15 & 180 \\
Sulfur dioxide & 35 & 180 \\
Carbon monoxide & 41 & 180 \\
$\mathrm{PM}_{10}$ & 68 & 180 \\
$\mathrm{PM}_{2.5}$ & 60 & 132 \\
\hline
\end{tabular}

Abbreviation: PM, particulate matter.

$\mathrm{PM}_{10}$ were higher in summer, while levels of $\mathrm{SO}_{2}, \mathrm{NO}_{2}$, and $\mathrm{CO}$ were higher in winter.

Since 1983, the death rates of three studied diseases have been decreasing (Figure 3), with declines in emphysema death rates more dramatic since 1998, for asthma since 1995, and for pneumonia since 1990. From 1993 to 2010, 101,374 deaths in North Carolina were caused by pneumonia, 13,187 by emphysema, and 5,509 by asthma. The detailed description of the studied population is presented in Table 2. Among those who died from emphysema and from pneumonia, $80.7 \%$ and $85.9 \%$, respectively, were older than 65 years. For asthma, ages at death were younger: $9.7 \%$ were younger than 40 years, and $31.3 \%$ were aged $40-64$ years old. However, the declining trends of pollutant concentrations and death rates during 1993-2010 do not essentially confirm causality.

The association between the changes of air-pollutant levels and dynamics of disease-specific death rates after being adjusted for smoking prevalence (for respective year and age-group), and by monthly fluctuations in respiratory disease-specific death rates are shown in Table 3, for each air pollutant. The disease-specific death rate (number of deaths per 100,000 population) decreased by a factor calculated based on the value of estimate presented in Table 3 (ie, per decrease of concentration of each pollutant by one unit of measurement: per $1.0 \mathrm{ppb}$ for ozone, $\mathrm{SO}_{2}, \mathrm{NO}_{2}, \mathrm{CO}$, and per $1.0 \mu \mathrm{g} / \mathrm{m}^{3}$ for $\mathrm{PM}_{2.5}$ and $\left.\mathrm{PM}_{10}\right)$. For example, the estimate for emphysema in Table 3 means that if the $\mathrm{SO}_{2}$ level decreases by $1 \mathrm{ppb}$, the emphysema death rate (per 100,000 population) can be predicted to decrease by a factor of $\exp (0.0547)=1.056$. Similar interpretation can be developed for smoking estimates, keeping in mind that smoking is represented by its prevalence in population measured in percentages, and thus the respective exponential factor corresponds to a change in smoking prevalence by $1 \%$.

Among gaseous pollutants, the estimates for associations between reduction of air-pollutant levels and reduction of death rates were significant for $\mathrm{SO}_{2}$ and emphysema (0.0547 $\pm 0.0106, P<0.0001)$, asthma $(0.0598 \pm 0.0173$, 


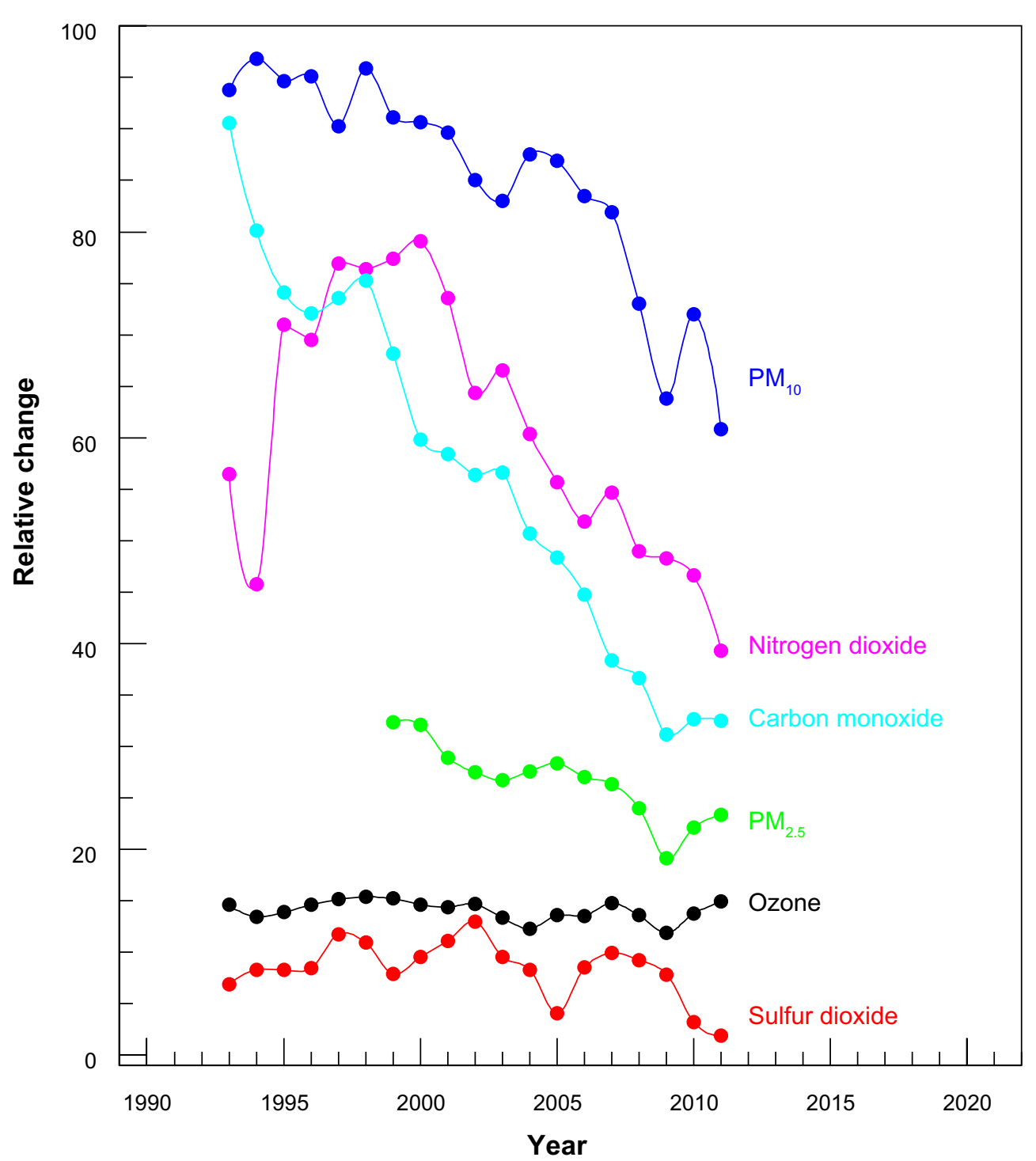

Figure I Levels of six air pollutants in North Carolina, 1993-20II. Individual pollutants were placed onto a single graph by utilizing arbitrary units to enable a collective visualization of the trends.

Abbreviation: PM, particulate matter.

$P<0.001)$, and pneumonia $(0.0309 \pm 0.0093, P<0.001)$, and for $\mathrm{CO}$ and emphysema $(0.0004 \pm 0.0001, P<0.0001)$ and asthma (0.0006 $\pm 0.0001, P<0.001)$. For $P M$, reduced $\mathrm{PM}_{2.5}$ levels were associated with reduction of emphysema mortality $(0.0155 \pm 0.0066, P<0.05)$ and reduced $P_{10}$ levels, with reduction of asthma mortality $(0.0204 \pm 0.0058, P<0.001)$. As expected, smoking significantly affected the mortality of each disease.

\section{Sensitivity analysis}

The sensitivity analysis demonstrated good stability of obtained results (see Table S1 for detailed information). In the sensitivity analysis, the association between pneumonia mortality and $\mathrm{CO}$ levels became significant ( $P=0.0655$ in main versus $P<0.0001$ in sensitivity analysis) when pneumonia was analyzed as an underlying cause of death. Recent studies have demonstrated that separation of comorbid conditions to underlying and secondary causes can be unreliable, ${ }^{23-25}$ however, for certain diseases with a predominantly acute course (eg, pneumonia), that may not be the case, and additional information can also be obtained from analysis of underlying causes of death. In addition, sensitivity analysis showed that during summer decreased mortality from emphysema was associated with lower levels of $\mathrm{PM}_{10}(P=0.2554$ in main versus $P=0.017$ in sensitivity analysis), and statistical significance was observed for associations between pneumonia mortality and $\mathrm{CO}$ levels when ICD code changes were taken into account $(P=0.0655$ in main versus $P=0.018$ in sensitivity analysis).

A county-level analysis also demonstrated the stability of most observations in the main analysis. Among associations 

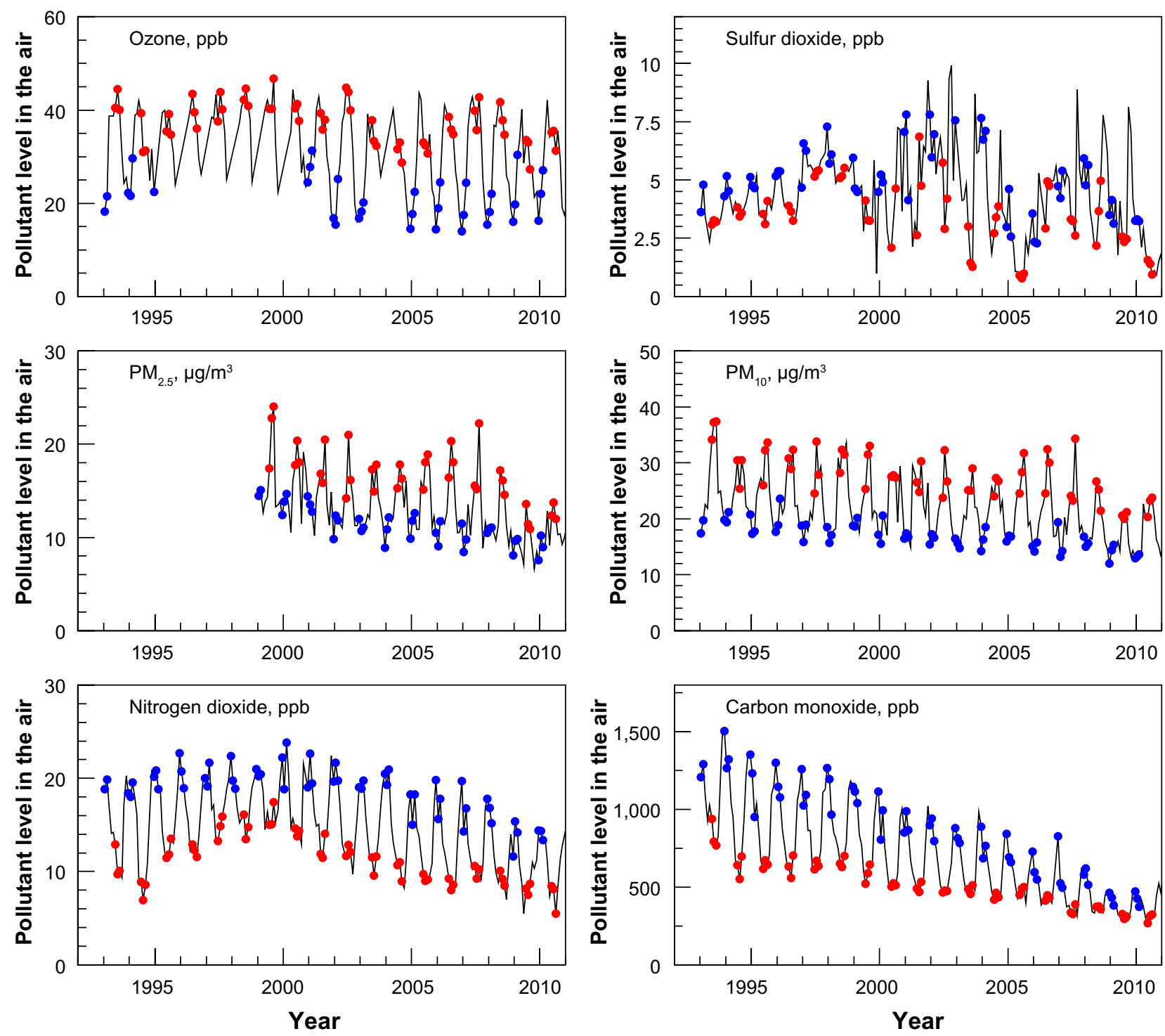

Figure 2 Seasonal fluctuations of air-pollutant levels: summer (red, 3 months) and winter (blue, 3 months), 1993-20II. Abbreviation: PM, particulate matter.
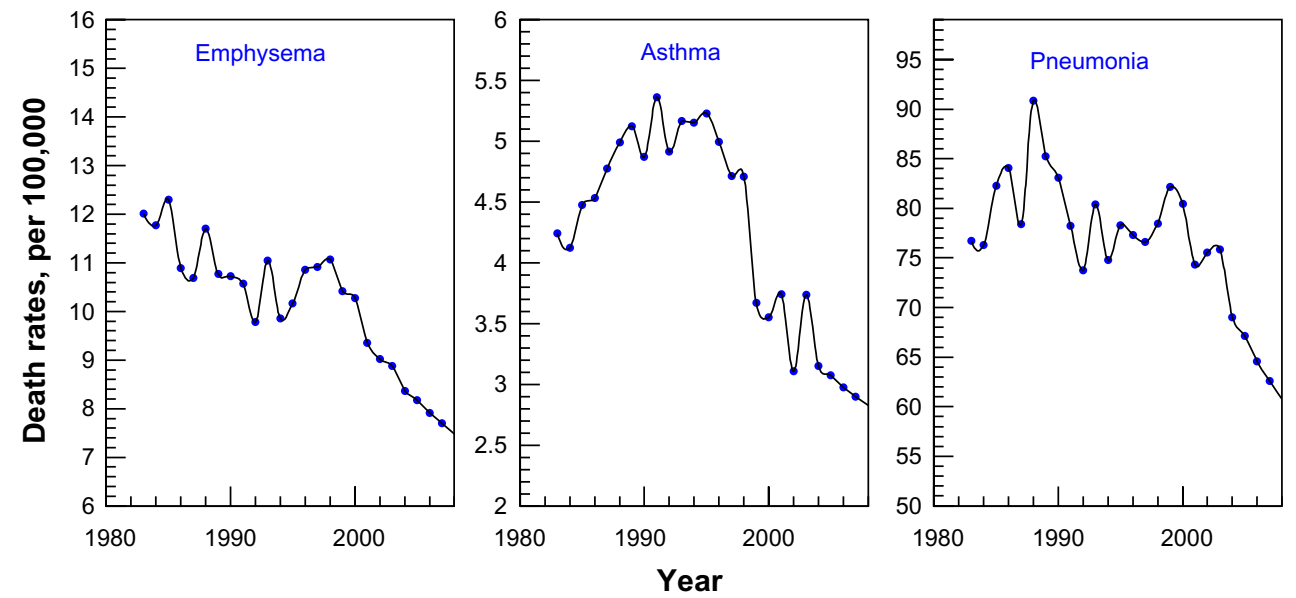

Figure 3 Trends in death rates for emphysema, asthma, and pneumonia in North Carolina, 1983-2010. Mortality rates were age-adjusted to the 2000 North Carolina population. 
Table 2 Demographic characteristics of North Carolina population with cause-specific respiratory mortality, 1993-2010

\begin{tabular}{|c|c|c|c|}
\hline \multirow{2}{*}{$\begin{array}{l}\text { Demographic } \\
\text { characteristic }\end{array}$} & \multicolumn{3}{|l|}{ Cause of death } \\
\hline & Emphysema & Asthma & Pneumonia \\
\hline Number of deaths & 13,187 & 5,509 & 10,1374 \\
\hline \multicolumn{4}{|l|}{ Sex, $n$} \\
\hline Males & 7,951 (60.3\%) & I,806 (32.8\%) & 48,517 (47.9\%) \\
\hline Females & $5,236(39.7 \%)$ & $3,703(67.2 \%)$ & $52,857(52.1 \%)$ \\
\hline \multicolumn{4}{|l|}{ Race, $n$} \\
\hline Caucasians & I I,866 (90.0\%) & 3,567 (64.8\%) & 82,759 (81.6\%) \\
\hline African-Americans & I,237 (9.4\%) & I,853 (33.6\%) & I7,665 (I7.4\%) \\
\hline Other & $84(0.6 \%)$ & 89 (1.6\%) & $950(1.0 \%)$ \\
\hline \multicolumn{4}{|l|}{ Age, $n$} \\
\hline$<15$ years old & $7(0.1 \%)$ & $103(1.9 \%)$ & $595(0.6 \%)$ \\
\hline $15-39$ years old & $40(0.3 \%)$ & 429 (7.8\%) & $\mathrm{I}, 633(1.6 \%)$ \\
\hline 40-64 years old & $2,504(19.0 \%)$ & I,723 (31.3\%) & |2,054 (| I.9\%) \\
\hline $65+$ years old & $10,636(80.7 \%)$ & 3,254 (59.1\%) & 87,091 (85.9\%) \\
\hline
\end{tabular}

that were significant under Bonferroni correction in the main analysis, associations between dynamics of $\mathrm{SO}_{2}$ and mortality from emphysema $(0.1399, P<0.001)$ and pneumonia (0.0698, $P<0.001)$, and associations between changes of CO levels and asthma mortality $(0.0004, P<0.05)$ were also significant in the sensitivity analysis. The association between $\mathrm{CO}$ and pneumonia mortality was also significant when analysis was performed on a county level $(0.0002$, $P<0.001)$. Recall that this association was significant in the analysis using state-level data in two cases: when being corrected for changes of ICD codes and when only underlying causes of deaths were considered as contributing to the cause-specific death (see detailed results in Table S1). The effects of dynamics of $\mathrm{SO}_{2}$ and $\mathrm{PM}_{10}$ on asthma mortality became nonsignificant $(P>0.05)$, likely due to the small number of county-specific asthma deaths and due to the large fraction of zeroth death rates that were not successfully described by Equation 1.

\section{Discussion}

We found significant correlations between reduction of air pollutants and dynamics of deaths due to respiratory diseases during the period we studied. We need to contextualize these findings, particularly in regard to the multifactorial contributors to respiratory mortality. In general, COPD has been shown to correlate highly with air pollution linked to global urbanization, ${ }^{26} \mathrm{eg}$, higher prevalence of chronic bronchitis (odds ratio [OR] 2.26, confidence interval [CI] 1.54-3.31), asthma (OR 1.57, CI 1.25-1.98), and emphysema (OR 2.98, CI 1.95-4.54) were observed in the meta-analyses of individuals exposed to urban air. ${ }^{27}$ Little is known about whether chronic, low-dose exposure to ambient air pollutants can exacerbate COPD progression. ${ }^{28,29}$ Several recent studies related respiratory symptoms to long-term rather than short-term effects of ambient particles, ${ }^{30}$ with the long-term exposure to $\mathrm{PM}_{10}$ increasing the risk of COPD. ${ }^{31}$

Changing air quality in North Carolina could be a good example of analysis of the trends of both improved air quality and respiratory mortality over almost two decades of observations. Improved air quality in North Carolina since the mid-1990s is related to a series of federal and state acts and regulations (see Table 4), including the national heavy-duty truck engine standards, reduction of $\mathrm{NO}_{\mathrm{x}}$ emissions, the Clean Smokestacks Act, and new engine standards. Regulations of emissions of $\mathrm{NO}_{\mathrm{x}}, \mathrm{PM}_{10}$, and $\mathrm{CO}$ appeared to be very effective in improving air quality in the state. Observed seasonal fluctuations of air-pollutants levels could be due to seasondependent local dispersive conditions, breeze dynamics,

Table 3 Associations between trends in emphysema, asthma, and pneumonia death rates and dynamics of air pollutants in North Carolina, 1992-2010

\begin{tabular}{|c|c|c|c|}
\hline Potential health-impact factor & Emphysema & Asthma & Pneumonia \\
\hline Ozone, ppb & $0.006 \mathrm{I} \pm 0.0030, P<0.05$ & $0.0082 \pm 0.0056 *$ & $-0.001 I \pm 0.0019 *$ \\
\hline Smoking & $0.0493 \pm 0.0056^{\dagger}, P<0.0001$ & $0.0649 \pm 0.0105^{\dagger}, P<0.0001$ & $0.0413 \pm 0.0034^{\dagger}, P<0.000 \mathrm{I}$ \\
\hline $\mathrm{SO}_{2}, \mathrm{Ppb}$ & $0.0547 \pm 0.0106^{\dagger}, P<0.0001$ & $0.0598 \pm 0.0173^{\dagger}, P<0.001$ & $0.0309 \pm 0.0093^{\dagger}, P<0.001$ \\
\hline Smoking & $0.0399 \pm 0.0074^{\dagger}, P<0.0001$ & $0.0563 \pm 0.012 \mathrm{I}^{\dagger}, P<0.000 \mathrm{I}$ & $0.0360 \pm 0.0063^{\dagger}, P<0.000 \mathrm{I}$ \\
\hline $\mathrm{NO}_{2}, \mathrm{Ppb}$ & $0.0153 \pm 0.0062, P<0.01$ & $0.0270 \pm 0.0094, P<0.005$ & $0.0030 \pm 0.0053 *$ \\
\hline Smoking & $0.0456 \pm 0.0090^{\dagger}, P<0.0001$ & $0.05 \mathrm{II} \pm 0.0 \mathrm{I} 40^{\dagger}, P<0.00 \mathrm{I}$ & $0.0455 \pm 0.0076^{\dagger}, P<0.000 \mathrm{I}$ \\
\hline $\mathrm{CO}, \mathrm{ppb}$ & $0.0004 \pm 0.000 \mathrm{I}^{\dagger}, P<0.000 \mathrm{I}$ & $0.0006 \pm 0.000 \mathrm{I}^{\dagger}, P<0.000 \mathrm{I}$ & $0.000 I \pm 0.000 I *$ \\
\hline Smoking & $0.0300 \pm 0.0083^{\dagger}, P<0.001$ & $0.0349 \pm 0.0129, P<0.01$ & $0.0388 \pm 0.0074^{\dagger}, P<0.000 \mathrm{I}$ \\
\hline $\mathrm{PM}_{2.5}, \mu \mathrm{g} / \mathrm{m}^{3}$ & $0.0155 \pm 0.0066, P<0.05$ & $0.0116 \pm 0.0083 *$ & $0.0044 \pm 0.0063^{*}$ \\
\hline Smoking & $0.0414 \pm 0.0072^{\dagger}, P<0.000 \mathrm{I}$ & $0.0329 \pm 0.0093^{\dagger}, P<0.00$ I & $0.0462 \pm 0.0067^{\dagger}, P<0.000 \mathrm{I}$ \\
\hline $\mathrm{PM}_{10}, \mu \mathrm{g} / \mathrm{m}^{3}$ & $0.0045 \pm 0.0039 *$ & $0.0204 \pm 0.0058^{\dagger}, P<0.00$ I & $-0.0015 \pm 0.0035^{*}$ \\
\hline Smoking & $0.0583 \pm 0.0069 \dagger, P<0.0001$ & $0.0644 \pm 0.0109^{\dagger}, P<0.0001$ & $0.0499 \pm 0.0057^{\dagger}, P<0.000 \mathrm{I}$ \\
\hline
\end{tabular}

Notes: For each air pollutant, the effect of smoking was evaluated. The effects of month-to-month fluctuations in disease-specific mortality for emphysema, asthma, and pneumonia are not shown in the table, but they also were evaluated for each month. $* P>0.05$; ${ }^{\dagger}$ significant under Bonferroni correction for multiple comparisons. Abbreviation: PM, particulate matter. 


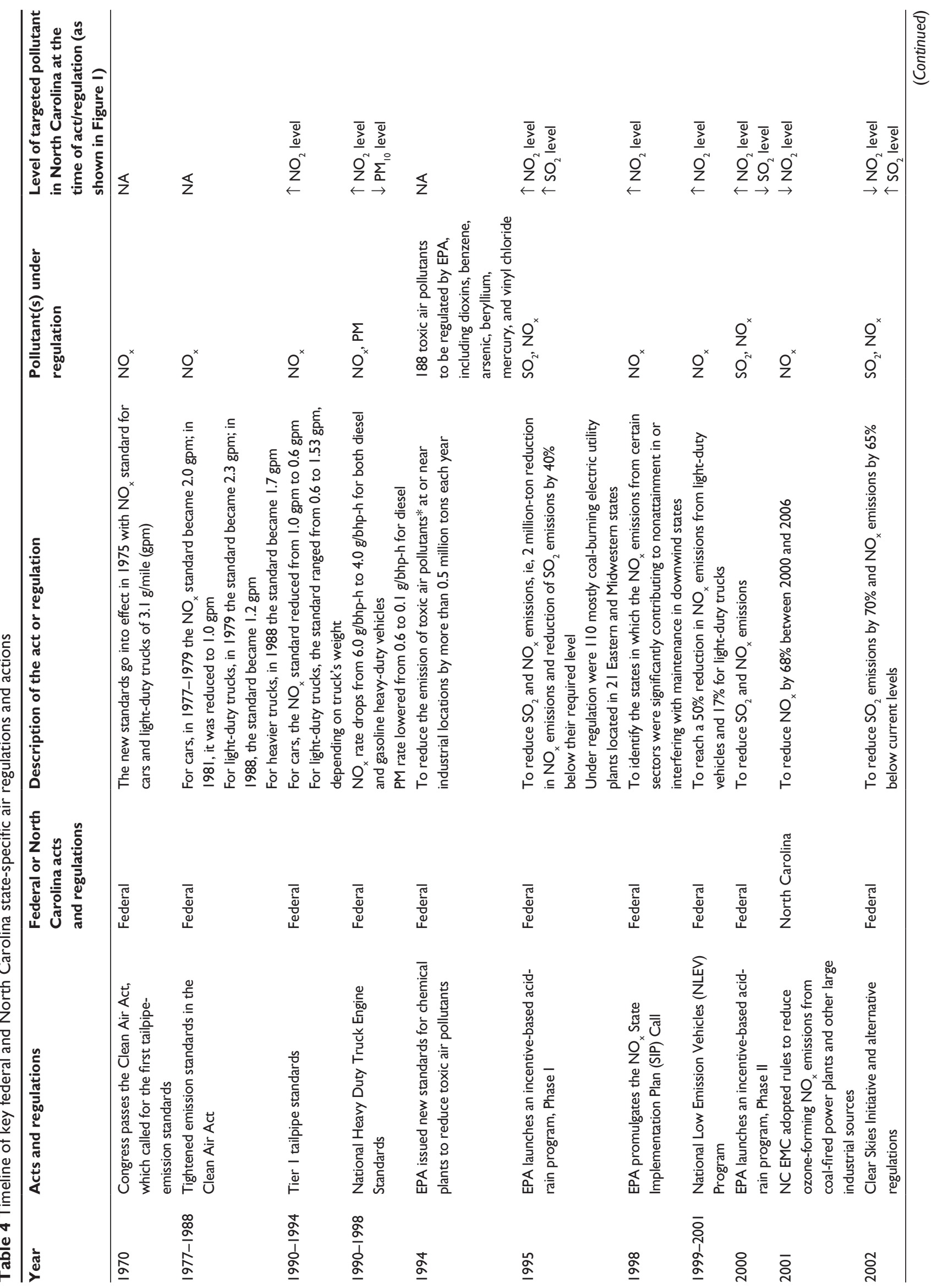




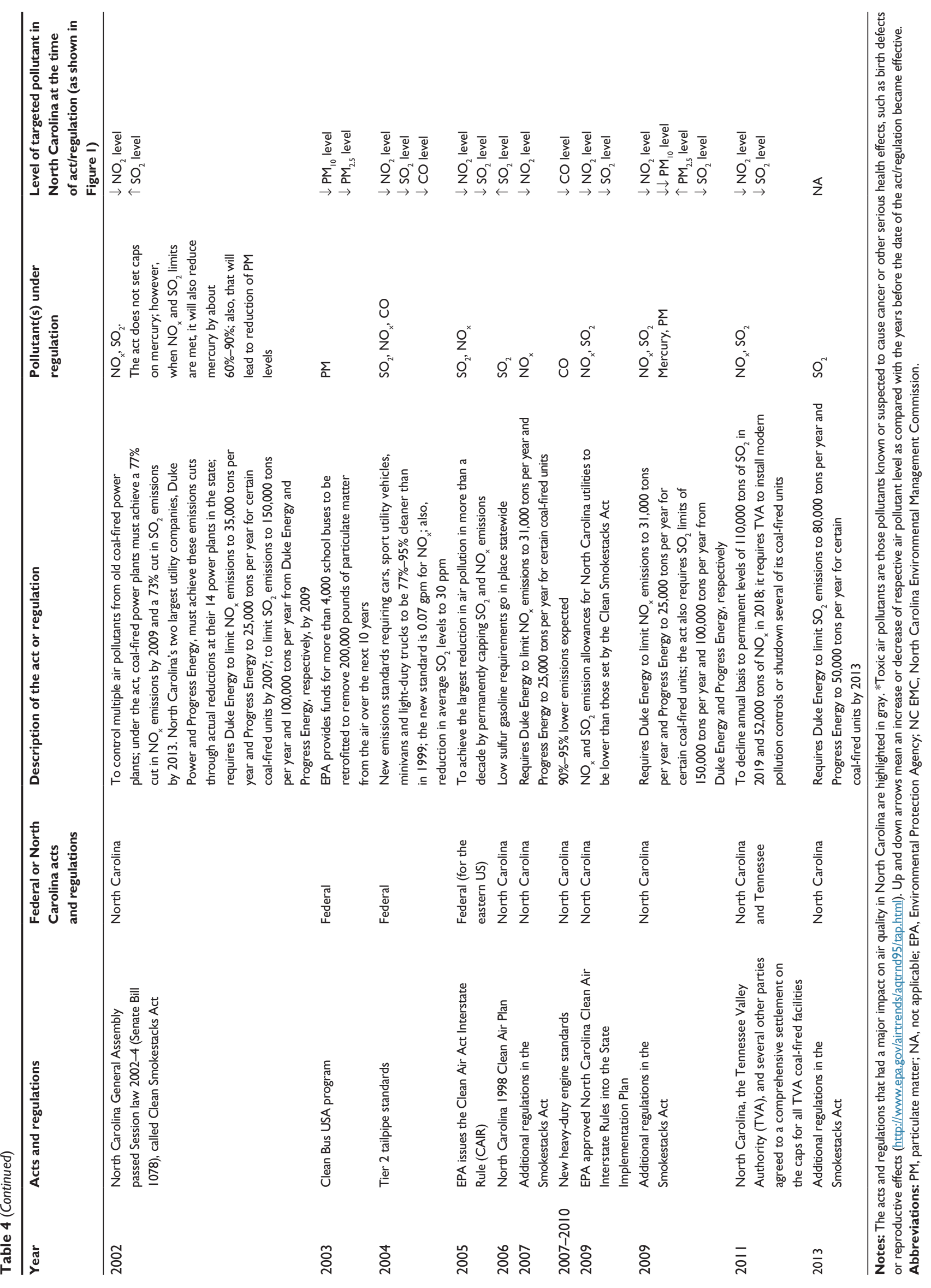


differences in concentration process (eg, caused by the thinning of the air mixing layer in winter), and season-specific higher formation of certain compounds, eg, higher nitrate formation in the cold season leads to higher levels of $\mathrm{NO}_{\mathrm{x}}$ in the air. ${ }^{32}$ Higher PM levels observed in North Carolina during the summer are of additional concern for health effects being exacerbated by hot humid weather, especially during heat waves. ${ }^{33}$ For respiratory mortality, no threshold effect has been identified; ${ }^{34,35}$ therefore, detailed economic analysis is required to evaluate the expenses and benefits of keeping the levels of air pollutants extra low. For current regulations in the US, it has been shown that control of $\mathrm{PM}_{2.5}$ emissions could result in $\$ 100$ billion of benefits annually. ${ }^{36}$

\section{Air quality and emphysema}

In our study, the association between reduced levels of ozone, $\mathrm{SO}_{2}, \mathrm{NO}_{2}, \mathrm{CO}$, and $\mathrm{PM}_{2.5}$ and decreased mortality from emphysema were observed, with associations for $\mathrm{SO}_{2}$ and $\mathrm{CO}$ remaining significant under Bonferroni correction. In other studies, emphysema outcomes were usually analyzed as a part of COPD; nonetheless, our findings on emphysema are in general agreement with these publications. For example, higher prevalence of visits to emergency departments for COPD and emphysema have been observed for higher $\mathrm{SO}_{2}$ levels ${ }^{37}$ (especially among older adults $\left.{ }^{38}\right)$; however, some studies showed that these associations may be attributable to $\mathrm{SO}_{2}$ serving as a surrogate of other substances. ${ }^{39}$ Few studies are available on the effects of outdoor CO on COPD..$^{40,41}$ Our results on associations between lower $\mathrm{CO}$ levels and lower emphysema mortality are in agreement with studies that showed increased morbidity and mortality risks among patients with COPD. ${ }^{42-45}$ Note that the impacts of $\mathrm{CO}$ could be effectively minimized by controlling transportation activities, which accounts for more than three-quarters of CO emissions in the US. ${ }^{42,46}$ While in our study associations with $\mathrm{PM}_{2.5}$ became nonsignificant under Bonferroni correction, in other studies higher levels of $\mathrm{PM}_{2.5}$ have been associated with higher admissions for COPD exacerbation ${ }^{47}$ and with increased COPD mortality. ${ }^{48-50}$ These differences could be due to the fact that the aforementioned studies were performed outside the US, had different patterns of seasonal fluctuations of PM levels in the air, and also were focused on specific populations (ie, older adults).

\section{Air quality and asthma}

We observed decreasing asthma mortality associated with lower levels of $\mathrm{NO}_{2}, \mathrm{SO}_{2}, \mathrm{CO}$, and $\mathrm{PM}_{10}$, with the latter three pollutants remaining significant under Bonferroni correction. These results are in agreement with other studies.
For example, correlations have been reported between asthma mortality and $\mathrm{SO}_{2}{ }^{51}$ and $\mathrm{NO}_{2}{ }^{52-56}$ levels, and between asthma severity (in children) and CO levels. ${ }^{43,44,57}$ Other studies reported that asthma mortality decreased earlier in response to improvement of air quality (eg, when compared to emphysema or chronic bronchitis), ${ }^{51}$ with a decrease of asthma deaths occurring approximately 5 years earlier.

The effects of PMs on respiratory health and, in particular, on asthma have been studied predominantly for associations with prevalence of respiratory symptoms ${ }^{58-60}$ and emergency department visits or hospital admissions. ${ }^{28,61-63}$ It has been shown that asthma symptoms were exacerbated even at PMs concentrations being $60 \%$ below the safety limits for PMs (ie, that supposed not to affect the healthy population). ${ }^{64}$ However, information on associations of asthma mortality with longterm exposure to PMs is sparse. In our study, reduction of $\mathrm{PM}_{10}$ (and its seasonal fluctuations) was associated with decreased asthma mortality in North Carolina. Previous studies on $\mathrm{PM}_{10}$ showed that elevated levels of $\mathrm{PM}_{10}$ were correlated with hospital admissions for asthma among patients aged 65+ years ${ }^{65}$ and children, ${ }^{44,57}$ and also with increased use of asthma medications among patients aged from 8 to 72 years old. ${ }^{66}$

Because air-quality and asthma-aggravation associations are reported from the studies typically performed in a single geographic region over a single season, individual study results may not be applicable to different populations and to longer weather/season cycles. ${ }^{43}$ Also, different components of PMs (eg, sulfates, nitrates, organic chemicals, metals, and soil or dust particles $)^{12}$ may have different effects on the respiratory system. ${ }^{16,34,67}$ This makes comparisons between the studies challenging and may explain the diversity of results on health effects of PMs on both geographic and temporal scales. ${ }^{68}$

\section{Air quality and pneumonia}

In our study, a decrease in pneumonia deaths was associated with decreasing $\mathrm{SO}_{2}$ levels. Also, when pneumonia was considered as the underlying cause of death, lower pneumonia death rates were observed for lower CO levels. Some studies have linked an acute respiratory disease with higher levels of $\mathrm{SO}_{2}$ pollution, independently of cigarette smoking, ${ }^{69}$ while later studies have not confirmed these associations (however, some results were sensitive to the methods used to estimate air-pollutant levels)..$^{70,71}$ For $\mathrm{CO}$, an association has been reported between its increased concentrations and higher pneumonia hospitalization. ${ }^{45}$

While some epidemiological and experimental studies have suggested relationships between $\mathrm{NO}_{2}$, ozone, and PMs and increased risk for viral respiratory infections, ${ }^{72}$ we 
did not find these associations in our study. Our results are in agreement with another study that did not find positive associations between PMs and pneumonia deaths (they found associations only for the group of never-smokers). ${ }^{73}$ However, most of the studies were performed on pneumonia morbidity (including hospitalizations and emergency department visits), while our study was on mortality. Also, multiple reports on associations between pneumonia risk and PMs levels come from international studies, eg, from Europe (where PMs levels peak in winter), while on the East Coast of the US they typically peak in summer, ${ }^{74}$ as we also observed in our study. While pneumonia is more frequent in late fall and winter, the relationships between outdoor air quality and health are supposed to be stronger in summer, when people spend more time outdoors. A study from Boston also supports our findings: no associations with pneumonia hospital admissions were found in summer, while in winter the largest effect on pneumonia morbidity was reported not for PMs but for black carbon (a surrogate for traffic particles: 14.3\% increase of pneumonia hospitalizations for $1.7 \mu \mathrm{g} / \mathrm{m}^{3}$ increase of black carbon). ${ }^{45}$ Higher risk of morbidity and mortality from acute respiratory infections has been also reported for children exposed to $\mathrm{PM}_{10}{ }^{22,75-85}$ In our study, we did not estimate mortality risks specifically for children; future studies will be performed for age-groups that are potentially at highest risk (ie, children and older adults).

\section{Methodological aspects and study limitations}

In our approach, the number of observations sufficient to estimate model parameters was achieved by incorporating monthly changes of air-pollutant levels and respiratory mortality. One advantage of this approach is that the unobserved heterogeneity due to other factors (such as socioeconomic status, quality of health care, migration) is minimal, because these factors do not essentially vary from month to month. In contrast, this unobserved heterogeneity is typical for ecological studies with area-based design, and could result in the occurrence of additional biases if these variables are not sufficiently controlled.

One example of such a factor is the time trend describing improvements in the treatment of respiratory disease that occurred during the recent two decades and which contributed to decreasing trends of mortality from emphysema, asthma, and pneumonia. Both improved air quality and vaccinations against pneumonia could lead to fewer hospital admissions, eg, pneumonia age-adjusted death rates started declining in the late 1990s, while the hospital discharge rate did not change significantly for patients older than 15 years. ${ }^{86-88}$ Although our approach with measurements at the month level minimizes the bias from this time trend (because only a 12th of our measurements reflect the annual time trend), improvements in treatment (as well as factors other than air pollution and smoking with significant time trends) should be taken into account in further studies. For example, further analysis of disease-specific visits to emergency departments would be important to validate the role of improved medical care in observed respiratory disease trends.

Other factors, such as changes in socioeconomic status, can also impact the dynamics of disease-specific mortality rates. However, it has been reported that for social factors, as well as for race, the effects of modification, eg, of PMs (ie, $\mathrm{PM}_{10}$ ) on total mortality were weak. ${ }^{20}$

In our study, the time pattern of smoking was chosen to reflect annual trends in respiratory mortality in addition to air pollution. Inclusion of one additional variable measured annually (ie, not on a monthly basis) could result in difficulty in distinguishing the effect of this variable and smoking. Smoking was chosen because its patterns are concordant with patterns of respiratory mortality, and because of many substantive results on the role of smoking in respiratory mortality (eg, findings that both smoking and exposure to air pollutants [eg, $\mathrm{PM}_{2.5}$ ] could exacerbate respiratory diseases). ${ }^{28,73}$ In our study, smoking had a significant stable effect on the dynamics of respiratory mortality from all three studied diseases. However, it can also reflect possible impacts of other variables with similar to smoking time trends and associations with respiratory mortality. Better evaluation of smoking effects (including synergistic effects of smoking and air pollutants) could be achieved in studies with individual records on smoking status.

Study designs based on individual measurements of environmental exposure and health outcomes (which are classic epidemiologic approaches) would be helpful for improvement of the quality of estimates. However, such approaches are expensive and complex, in part due to the difficulty of measuring subjects' exposure to the relatively low levels of pollutants in the air. Some studies on the use of outdoor monitoring-station data (compared with the personal indoor/ outdoor-exposure monitors) demonstrated that personal exposure to pollutants of outdoor origin was more closely related to outdoor air-pollutant levels than interpretations of personal monitoring data. ${ }^{58,89}$ Furthermore, the frequently high correlations between levels of certain pollutants in the air also make it difficult to identify the impact of a single agent on human health. ${ }^{17}$ 
Changes in diagnostic criteria of respiratory diseases that happened during last two decades primarily affected the trends of disease incidence; however, in part, mortality trends were also affected. In children, diagnoses can transfer from chronic bronchitis and pneumonia to asthma, thus contributing to increasing trends in asthma prevalence (with its recent stabilization) and health care utilization. ${ }^{90}$ If the person dies from pneumonia, but also had an underlying condition of which the pneumonia was probably a result, than that underlying disease but not pneumonia is considered the cause of death in the death certificate, and thus fewer deaths are directly attributable to pneumonia. ${ }^{86}$ Although asthma death rates increased from 1980 to the mid-1990s, replaced ICD codes from the ninth to the tenth revision makes it challenging to evaluate the decline in asthma mortality since the late-1990s. ${ }^{91,92}$ With regard to this problem, it has been shown that decline in asthma mortality that occurred from 1998 to 1999 included approximately $11 \%$ of decline that resulted from the changes during the ICD codes transition; then, under ICD-10, asthma death rates continued declining. ${ }^{91}$ Because no definitive asthma laboratory tests exist, asthma estimates rely on the physician, who also should accurately attribute the cause of death to asthma; therefore, the reliability of the death certificates has been questioned (eg, for the chance of misreporting the cause of death in older persons with comorbid conditions). Large well-designed studies have concluded that asthma death coding has $99 \%$ specificity and low sensitivity (42\%), and asthma as a cause of death was underreported in preference to COPD in all age-groups. ${ }^{91,93}$

\section{Conclusion}

We observed temporal regional associations between long-term dynamics of decreasing death rates of emphysema, asthma, and pneumonia and reductions of the levels of certain air pollutants in North Carolina. Our results support the hypothesis that improvement in air quality, especially declines in $\mathrm{SO}_{2}, \mathrm{CO}$, and $\mathrm{PM}_{10}$ levels in the air, contributed to the improved respiratory health of the North Carolina population. Since other factors (in addition to the studied air pollutants) might also account for improved health outcomes, ultimately caution should be exercised in inferring cause-effect relations.

\section{Acknowledgment}

The authors thank Fred and Alice Stanback for supporting this study with a philanthropic donation to the Duke Cancer Center.

\section{Author contributions}

JK, WGR, and HKL developed the concept behind the study; JK and IA designed the study and carried out the data analysis with help from APA, SH, and HKL; JK wrote the paper with help from IA, and SH; APA, WGR, and HKL provided critical reviews of the manuscript. All authors have read and approved the final manuscript.

\section{Disclosure}

The authors report no competing conflicts of interest in this work.

\section{References}

1. Schwartz J, Dockery DW. Increased mortality in Philadelphia associated with daily air pollution concentrations. Am Rev Respir Dis. 1992;145(3): 600-604.

2. Pope CA 3rd, Thun MJ, Namboodiri MM, et al. Particulate air pollution as a predictor of mortality in a prospective study of US adults. Am J Respir Crit Care Med. 1995;151(3 Pt 1):669-674.

3. Touloumi G, Katsouyanni K, Zmirou D, et al. Short-term effects of ambient oxidant exposure on mortality: a combined analysis within the APHEA project. Air Pollution and Health: a European Approach. Am J Epidemiol. 1997;146(2):177-185.

4. Samet JM, Zeger SL, Dominici F, et al. The National Morbidity, Mortality, and Air Pollution Study. Res Rep Health Eff Inst. 2000; 94(Pt 2):5-79.

5. Katsouyanni K, Touloumi G, Samoli E, et al. Confounding and effect modification in the short-term effects of ambient particles on total mortality: results from 29 European cities within the APHEA2 project. Epidemiology. 2001;12(5):521-531.

6. Lipsman J, Frank AL. Attack on protections against air pollution. Am J Prev Med. 2011;41(6):645-647.

7. Ostro B. Outdoor Air Pollution: Assessing the Environmental Burden of Disease at National and Local Levels. Geneva: World Health Organization; 2004.

8. Pope C 3rd, Dockery D. Epidemiology of particle effects. In: Holgate ST, Koren H, Maynard R, Samet J, editors. Air Pollution and Health. San Diego: Academic; 1999:673-705.

9. Katsouyanni K, Touloumi G, Spix C, et al. Short-term effects of ambient sulphur dioxide and particulate matter on mortality in 12 European cities: results from time series data from the APHEA project. Air Pollution and Health: a European Approach. BMJ. 1997;314(7095):1658-1663.

10. Schwartz J. Air pollution and hospital admissions for cardiovascular disease in Tucson. Epidemiology. 1997;8(4):371-377.

11. Gryparis A, Forsberg B, Katsouyanni K, et al. Acute effects of ozone on mortality from the "Air Pollution and Health: a European Approach" project. Am J Respir Crit Care Med. 2004;170(10):1080-1087.

12. Spickett JT, Brown H, Rumchev K. Climate change and air quality: the potential impact on health. Asia Pac J Public Health. 2011; 23(Suppl 2):37S-45S.

13. Friedman MS, Powell KE, Hutwagner L, Graham LM, Teague WG. Impact of changes in transportation and commuting behaviors during the 1996 Summer Olympic Games in Atlanta on air quality and childhood asthma. JAMA. 2001;285(7):897-905.

14. Lin W, Huang W, Zhu T, et al. Acute respiratory inflammation in children and black carbon in ambient air before and during the 2008 Beijing Olympics. Environ Health Perspect. 2011;119(10):1507-1512.

15. Clancy L, Goodman P, Sinclair H, Dockery DW. Effect of air-pollution control on death rates in Dublin, Ireland: an intervention study. Lancet. 2002;360(9341):1210-1214.

16. Bell ML. Assessment of the health impacts of particulate matter characteristics. Res Rep Health Eff Inst. 2012;(161):5-38. 
17. Navidi W, Thomas D, Langholz B, Stram D. Statistical methods for epidemiologic studies of the health effects of air pollution. Res Rep Health Eff Inst. 1999;(86):1-56.

18. State of North Carolina. Session laws and resolutions passed by the 2001 General Assembly at its extra session 2002 and its regular session 2002. Available from: http://www.ncleg.net/EnactedLegislation/ SessionLawsCD/SessionLaws/2002SessionLaws.pdf. Accessed April 30, 2014.

19. Ross WG Jr. The North Carolina Clean Smokestacks Act. NC Med J. 2011;72(2):128-131.

20. Zanobetti A, Schwartz J, Gold D. Are there sensitive subgroups for the effects of airborne particles? Environ Health Perspect. 2000;108(9): 841-845.

21. Avol EL, Gauderman WJ, Tan SM, London SJ, Peters JM. Respiratory effects of relocating to areas of differing air pollution levels. Am J Respir Crit Care Med. 2001;164(11):2067-2072.

22. Braga AL, Zanobetti A, Schwartz J. The lag structure between particulate air pollution and respiratory and cardiovascular deaths in 10 US cities. J Occup Environ Med. 2001;43(11):927-933.

23. Redelings MD, Sorvillo F, Simon P. A comparison of underlying cause and multiple causes of death: US vital statistics, 2000-2001. Epidemiology. 2006;17(1):100-103.

24. McCoy L, Redelings M, Sorvillo F, Simon P. A multiple cause-of-death analysis of asthma mortality in the United States, 1990-2001. JAsthma. 2005;42(9):757-763.

25. Eric S. Underlying and multiple cause mortality at advanced ages: United States 1980-1998. N Am Actuar J. 2002;6(3):64-87.

26. Viegi G, Maio S, Pistelli F, Baldacci S, Carrozzi L. Epidemiology of chronic obstructive pulmonary disease: health effects of air pollution. Respirology. 2006;11(5):523-532.

27. Sancini A, Tomei F, Capozzella A, et al. Metanalysis: respiratory effects in the general population exposed to urban pollution. J Environ Prot (Irvine, Calif). 2011;2(7):974-981.

28. Ling SH, van Eeden SF. Particulate matter air pollution exposure: role in the development and exacerbation of chronic obstructive pulmonary disease. Int J Chron Obstruct Pulmon Dis. 2009;4:233-243.

29. Lipton R, Banerjee A, Dowling KC, Treno AJ. The geography of COPD hospitalization in California. COPD. 2005;2(4):435-444.

30. Karakatsani A, Andreadaki S, Katsouyanni K, et al. Air pollution in relation to manifestations of chronic pulmonary disease: a nested case-control study in Athens, Greece. Eur J Epidemiol. 2003;18(1): 45-53.

31. Schikowski T, Sugiri D, Ranft U, et al. Long-term air pollution exposure and living close to busy roads are associated with COPD in women. Respir Res. 2005;6(1):152.

32. Querol X, Alastuey A, Rodriguez S, et al. PM10 and PM2.5 source apportionment in the Barcelona metropolitan area, Catalonia, Spain. Atmos Environ. 2001;35(36):6407-6419.

33. Kravchenko J, Abernethy AP, Fawzy M, Lyerly HK. Minimization of heatwave morbidity and mortality. Am J Prev Med. 2013;44(3): 274-282.

34. World Health Organization. WHO Air Quality Guidelines for Particulate Matter, Ozone, Nitrogen Dioxide and Sulfur Dioxide: Global Update 2005 - Summary of Risk Assessment. Geneva: WHO; 2006.

35. Daniels MJ, Dominici F, Samet JM, Zeger SL. Estimating particulate matter-mortality dose-response curves and threshold levels: an analysis of daily time-series for the 20 largest US cities. Am J Epidemiol. 2000;152(5):397-406.

36. Davidson K, Hallberg A, McCubbin D, Hubbell B. Analysis of PM2.5 using the Environmental Benefits Mapping and Analysis Program (BenMAP). J Toxicol Environ Health A. 2007;70(3-4): $332-346$.

37. Euler G, Abbey D, Magie AR, Hodgkin J. Chronic obstructive pulmonary disease symptom effects of long-term cumulative exposure to ambient levels of total suspended particulates and sulfur dioxide in California Seventh-Day Adventist residents. Arch Environ Health. 1987;42(4):213-222.
38. Martins LC, de Oliveira Latorre MR, Saldiva PH, Braga AL. Air pollution and emergency room visits due to chronic lower respiratory diseases in the elderly: an ecological time-series study in São Paulo, Brazil. $J$ Occup Environ Med. 2002;44(7):622-627.

39. Chen R, Huang W, Wong CM, et al. Short-term exposure to sulfur dioxide and daily mortality in 17 Chinese cities: the China air pollution and health effects study (CAPES). Environ Res. 2012;118: 101-106.

40. Lambert W, Samet J, Dockery D. Community air pollution. In: Rom WN, editor. Environmental and Occupational Medicine. Philadelphia: Lippincott-Raven; 1998:1501-1522.

41. Chen R, Pan G, Zhang Y, et al. Ambient carbon monoxide and daily mortality in three Chinese cities: the China Air Pollution and Health Effects Study (CAPES). Sci Total Environ. 2011;409(23): 4923-4928.

42. Bernard SM, Samet JM, Grambsch A, Ebi KL, Romieu I. The potential impacts of climate variability and change on air pollution-related health effects in the United States. Environ Health Perspect. 2001;109 Suppl 2: 199-209.

43. Schildcrout JS, Sheppard L, Lumley T, Slaughter JC, Koenig JQ, Shapiro GG. Ambient air pollution and asthma exacerbations in children: an eight-city analysis. Am J Epidemiol. 2006;164(6):505-517.

44. Slaughter JC, Lumley T, Sheppard L, Koenig JQ, Shapiro GG. Effects of ambient air pollution on symptom severity and medication use in children with asthma. Ann Allergy Asthma Immunol. 2003;91(4):346-353.

45. Zanobetti A, Schwartz J. Air pollution and emergency admissions in Boston, MA. J Epidemiol Community Health. 2006;60(10):890-895.

46. US Environmental Protection Agency. National Air Quality and Emission Trends Report. Washington: EPA Office of Air Quality Planning and Standards; 1997.

47. Dominici F, Peng RD, Bell ML, et al. Fine particulate air pollution and hospital admission for cardiovascular and respiratory diseases. JAMA. 2006;295(10):1127-1134.

48. Næss $\varnothing$, Nafstad P, Aamodt G, Claussen B, Rosland P. Relation between concentration of air pollution and cause-specific mortality: four-year exposures to nitrogen dioxide and particulate matter pollutants in 470 neighborhoods in Oslo, Norway. Am J Epidemiol. 2007;165(4): 435-443.

49. Morrow PE, Utell MJ, Bauer MA, et al. Pulmonary performance of elderly normal subjects and subjects with chronic obstructive pulmonary disease exposed to $0.3 \mathrm{ppm}$ nitrogen dioxide. Am Rev Respir Dis. 1992;145(2 Pt 1):291-300.

50. Sunyer J, Basagaña X. Particles, and not gases, are associated with the risk of death in patients with chronic obstructive pulmonary disease. Int J Epidemiol. 2001;30(5):1138-1140.

51. Imai M, Yoshida K, Kitabatake M. Mortality from asthma and chronic bronchitis associated with changes in sulfur oxides air pollution. Arch Environ Health. 1986;41(1):29-35.

52. Saez M, Tobias A, Muñoz P, Campbell M. A GEE moving average analysis of the relationship between air pollution and mortality for asthma in Barcelona, Spain. Stat Med. 1999;18(16):2077-2086.

53. Sunyer J, Basagaña X, Belmonte J, Anto J. Effect of nitrogen dioxide and ozone on the risk of dying in patients with severe asthma. Thorax. 2002;57(8):687-693.

54. Blomberg A, Krishna MT, Bocchino V, et al. The inflammatory effects of 2 ppm $\mathrm{NO}_{2}$ on the airways of healthy subjects. Am J Respir Crit Care Med. 1997;156(2):418-424.

55. Samoli E, Aga E, Touloumi G, et al. Short-term effects of nitrogen dioxide on mortality: an analysis within the APHEA project. Eur Respir J. 2006;27(6):1129-1138.

56. Folinsbee L. Does nitrogen dioxide exposure increase airways responsiveness? Toxicol Ind Health. 1992;8(5):273-283.

57. Yu O, Sheppard L, Lumley T, Koenig JQ, Shapiro GG. Effects of ambient air pollution on symptoms of asthma in Seattle-area children enrolled in the CAMP study. Environ Health Perspect. 2000;108(12): 1209-1214. 
58. Schwartz J. Assessing confounding, effect modification, and thresholds in the association between ambient particles and daily deaths. Environ Health Perspect. 2000;108(6):563-568.

59. Global initiative for chronic Obstructive Lung Disease (GOLD). Global Strategy for the Diagnosis, Management, and Prevention of Chronic Obstructive Pulmonary Disease. Bethesda (MD): GOLD; 2013.

60. Anthonisen NR, Connett JE, Kiley JP, et al. Effects of smoking intervention and the use of an inhaled anticholinergic bronchodilator on the rate of decline of $\mathrm{FEV}_{1}$. JAMA. 1994;272(19):1497-1505.

61. Gilmour PS, Ziesenis A, Morrison ER, et al. Pulmonary and systemic effects of short-term inhalation exposure to ultrafine carbon black particles. Toxicol Appl Pharmacol. 2004;195(1):35-44.

62. Johnson RL. Relative effects of air pollution on lungs and heart. Circulation. 2004;109(1):5-7.

63. Stuart BO. Deposition and clearance of inhaled particles. Environ Health Perspect. 1976;16:41-53.

64. Schwartz J, Slater D, Larson TV, Pierson WE, Koenig JQ. Particulate air pollution and hospital emergency room visits for asthma in Seattle. Am Rev Respir Dis. 1993;147(4):826-831.

65. Atkinson RW, Anderson HR, Sunyer J, et al. Acute effects of particulate air pollution on respiratory admissions: results from APHEA 2 project. Am J Respir Crit Care Med. 2001;164(10):1860-1866.

66. Pope CA 3rd, Dockery DW, Spengler JD, Raizenne ME. Respiratory health and PM10 pollution. A daily time series analysis. Am Rev Respir Dis. 1991;144(3 Pt 1):668-674.

67. Nel AE, Diaz-Sanchez D, Li N. The role of particulate pollutants in pulmonary inflammation and asthma: evidence for the involvement of organic chemicals and oxidative stress. Curr Opin Pulm Med. 2001;7(1): 20-26.

68. Leikauf GD, Kline S, Albert RE, Baxter CS, Bernstein DI, Buncher CR Evaluation of a possible association of urban air toxics and asthma. Environ Health Perspect. 1995;103 Suppl 6:253-271.

69. French JG, Lowrimore G, Nelson WC, Finklea JF, English T, Hertz M. The effect of sulfur dioxide and suspended sulfates on acute respiratory disease. Arch Environ Health. 1973;27(3):129-133.

70. Neupane B, Jerrett M, Burnett RT, Marrie T, Arain A, Loeb M. Longterm exposure to ambient air pollution and risk of hospitalization with community-acquired pneumonia in older adults. Am J Respir Crit Care Med. 2010;181(1):47-53.

71. Wong TW, Lau TS, Yu TS, et al. Air pollution and hospital admissions for respiratory and cardiovascular diseases in Hong Kong. Occup Environ Med. 1999;56(10):679-683.

72. Ciencewicki J, Jaspers I. Air pollution and respiratory viral infection. Inhal Toxicol. 2007;19(14):1135-1146.

73. Pope CA 3rd, Burnett RT, Thurston GD, et al. Cardiovascular mortality and long-term exposure to particulate air pollution: epidemiological evidence of general pathophysiological pathways of disease. Circulation. 2004;109(1):71-77.

74. Hoek G, Brunekreef B, Verhoeff A, van Wijnen J, Fischer P. Daily mortality and air pollution in the Netherlands. J Air Waste Manag Assoc. 2000;50(8):1380-1389.

75. Conceição G, Miraglia S, Kishi HS, Saldiva P, Singer JM. Air pollution and child mortality: a time-series study in São Paulo, Brazil. Environ Health Perspect. 2001;109 Suppl 3:347-350.

76. Gouveia N, Fletcher T. Respiratory diseases in children and outdoor air pollution in Sao Paulo, Brazil: a time series analysis. Occup Environ Med. 2000;57(7):477-483.
77. Saldiva PH, Lichtenfels A, Paiva P, et al. Association between air pollution and mortality due to respiratory diseases in children in São Paulo, Brazil: a preliminary report. Environ Res. 1994;65(2):218-225.

78. Hernández-Cadena L, Barraza-Villarreal A, Ramírez-Aguilar M, et al. [Infant morbidity caused by respiratory diseases and its relation with the air pollution in Juarez City, Chihuahua, Mexico]. Salud Publica Mex. 2007;49(1):27-36. Spanish.

79. Ostro BD, Eskeland GS, Sanchez JM, Feyzioglu T. Air pollution and health effects: a study of medical visits among children in Santiago, Chile. Environ Health Perspect. 1999;107(1):69-73.

80. Dominici F, Daniels M, Zeger SL, Samet JM. Air pollution and mortality: estimating regional and national dose-response relationships. J Am Stat Assoc. 2002;97(457):100-111.

81. Barnett AG, Williams GM, Schwartz J, et al. Air pollution and child respiratory health: a case-crossover study in Australia and New Zealand. Am J Respir Crit Care Med. 2005;171(11):1272-1278.

82. Ngo L, Mehta S, Do D, Thach T. The effects of short-term exposure on hospital admissions for acute lower respiratory infections in young children of Ho Chi Minh City, Viet Nam. Epidemiology. 2011;22(1): S228-S229.

83. Karr C, Lumley T, Shepherd K, et al. A case-crossover study of wintertime ambient air pollution and infant bronchiolitis. Environ Health Perspect. 2006;114(2):277-281.

84. Segala C, Poizeau D, Mesbah M, Willems S, Maidenberg M. Winter air pollution and infant bronchiolitis in Paris. Environ Res. 2008;106(1): 96-100.

85. Cohen AJ, Anderson HR, Ostro B, et al. Urban air pollution. In: Ezzati M, Lopez AD, Rodgers A, Murray CJ. Comparative Quantification of Health Risks. Geneva: WHO; 2004:1353-1433.

86. American Lung Association. Trends in Pneumonia and Influenza Morbidity and Mortality. Chicago: ALA; 2010.

87. Getahun D, Demissie K, Rhoads GG. Recent trends in asthma hospitalization and mortality in the United States. J Asthma. 2005;42(5): 373-378.

88. Li YC, Norton EC, Dow WH. Influenza and pneumococcal vaccination demand responses to changes in infectious disease mortality. Health Serv Res. 2004;39(4 Pt 1):905-926.

89. Janssen NA, Hoek G, Brunekreef B, Harssema H, Menswik I, Zuidhof A. Personal sampling of particles in adults: relation among personal, indoor, and outdoor air concentrations. Am J Epidemiol. 1998;147(6):537-547.

90. Akinbami LJ, Schoendorf KC. Trends in childhood asthma: prevalence, health care utilization, and mortality. Pediatrics. 2002;110(2): 315-322.

91. Moorman JE, Rudd RA, Johnson CA, et al. National surveillance for asthma - United States, 1980-2004. MMWR Surveill Summ. 2007;56(8): $1-54$.

92. Loddenkemper R. European Lung White Book: The First Comprehensive Survey on Respiratory Health in Europe. Lausanne, Switzerland: European Respiratory Society; 2003.

93. Hunt LW Jr, Silverstein MD, Reed CE, O’Connell EJ, O'Fallon WM, Yunginger JW. Accuracy of the death certificate in a population-based study of asthmatic patients. JAMA. 1993;269(15):1947-1952. 


\section{Supplementary material}

Table SI Results of the sensitivity analysis

\begin{tabular}{|c|c|c|c|}
\hline Potential health-impact factor & Emphysema & Asthma & Pneumonia \\
\hline & Analysis I (ICD-9/I0) & Analysis I (ICD-9/I0) & Analysis I (ICD-9//0) \\
\hline Ozone, ppb & $0.0056 \pm 0.0029, P>0.05$ & $0.0052 \pm 0.0050, P>0.05$ & $-0.001 \mathrm{I} \pm 0.0019, P>0.05$ \\
\hline \multirow[t]{2}{*}{ Smoking } & $0.0433 \pm 0.0057, P<0.000$ I & $0.0427 \pm 0.0097, P<0.000 I$ & $0.04 \mathrm{I} I \pm 0.0036, P<0.000 \mathrm{I}$ \\
\hline & Analysis 2 (summer) & Analysis 2 (summer) & Analysis 2 (summer) \\
\hline Ozone, ppb & $0.0043 \pm 0.0069, P>0.05$ & $-0.0004 \pm 0.0085, P>0.05$ & $-0.0046 \pm 0.0024, P>0.05$ \\
\hline \multirow[t]{2}{*}{ Smoking } & $0.0777 \pm 0.0159, P<0.0001$ & $0.1|40 \pm 0.0205, P<0.000|$ & $0.0403 \pm 0.005 \mathrm{I}, P<0.000 \mathrm{I}$ \\
\hline & Analysis 3 (winter) & Analysis 3 (winter) & Analysis 3 (winter) \\
\hline Ozone, ppb & $0.0092 \pm 0.0037, P<0.01$ & $0.0004 \pm 0.0098, P>0.05$ & $0.0052 \pm 0.0056, P>0.05$ \\
\hline \multirow[t]{2}{*}{ Smoking } & $0.0377 \pm 0.0066, P<0.000 \mathrm{I}$ & $0.0104 \pm 0.0153, P>0.05$ & $0.024 I \pm 0.0101, P<0.05$ \\
\hline & Analysis 4 (underlying) & Analysis 4 (underlying) & Analysis 4 (underlying) \\
\hline Ozone, ppb & $0.0039 \pm 0.0031, P>0.05$ & $-0.0003 \pm 0.0084, P>0.05$ & $0.0054 \pm 0.0049, P>0.05$ \\
\hline \multirow[t]{2}{*}{ Smoking } & $0.0524 \pm 0.0056, P<0.000$ I & $0.0682 \pm 0.0156, P<0.0001$ & $0.08|4 \pm 0.0097, P<0.000|$ \\
\hline & Analysis I (ICD-9/I0) & Analysis I (ICD-9/I0) & Analysis I (ICD-9//0) \\
\hline $\mathrm{SO}_{2}, \mathrm{Ppb}$ & $0.0502 \pm 0.0108, P<0.0001$ & $0.0289 \pm 0.0159, P>0.05$ & $0.033 \mathrm{I} \pm 0.0094, P<0.00 \mathrm{I}$ \\
\hline \multirow[t]{2}{*}{ Smoking } & $0.036 \mathrm{I} \pm 0.0075, P<0.000 \mathrm{I}$ & $0.0375 \pm 0.0109, P<0.001$ & $0.0379 \pm 0.0064, P<0.0001$ \\
\hline & Analysis 2 (summer) & Analysis 2 (summer) & Analysis 2 (summer) \\
\hline $\mathrm{SO}_{2}, \mathrm{Ppb}$ & $0.055 \mathrm{I} \pm 0.0189, P<0.05$ & $0.0535 \pm 0.023 \mathrm{I}, P<0.05$ & $0.0027 \pm 0.0077, P>0.05$ \\
\hline \multirow[t]{2}{*}{ Smoking } & $0.065 I \pm 0.0145, P<0.000 I$ & $0.0978 \pm 0.0188, P<0.0001$ & $0.0345 \pm 0.0052, P<0.0001$ \\
\hline & Analysis 3 (winter) & Analysis 3 (winter) & Analysis 3 (winter) \\
\hline $\mathrm{SO}_{2}, \mathrm{Ppb}$ & $0.0823 \pm 0.0243, P<0.00 \mathrm{I}$ & $0.0298 \pm 0.0357, P>0.05$ & $0.0596 \pm 0.0250, P<0.05$ \\
\hline \multirow[t]{2}{*}{ Smoking } & $0.0386 \pm 0.0167, P<0.0001$ & $0.0432 \pm 0.0247, P>0.05$ & $0.0194 \pm 0.0170, P>0.05$ \\
\hline & Analysis 4 (underlying) & Analysis 4 (underlying) & Analysis 4 (underlying) \\
\hline $\mathrm{SO}_{2}, \mathrm{ppb}$ & $0.0358 \pm 0.0126, P<0.005$ & $0.0387 \pm 0.0259, P>0.05$ & $0.1094 \pm 0.0193, P<0.0001$ \\
\hline \multirow[t]{2}{*}{ Smoking } & $0.047 I \pm 0.0087, P<0.000 I$ & $0.0724 \pm 0.0180, P<0.0001$ & $0.0666 \pm 0.0140, P<0.000 \mid$ \\
\hline & Analysis I (ICD-9/I0) & Analysis I (ICD-9//0) & Analysis I (ICD-9//0) \\
\hline $\mathrm{NO}_{2}$, ppb & $0.0159 \pm 0.0062, P<0.01$ & $0.028 I \pm 0.0084, P<0.00 I$ & $0.0029 \pm 0.0053, P>0.05$ \\
\hline \multirow[t]{2}{*}{ Smoking } & $0.0367 \pm 0.0094, P<0.000$ I & $0.0179 \pm 0.0129, P>0.05$ & $0.0469 \pm 0.0079, P<0.0001$ \\
\hline & Analysis 2 (summer) & Analysis 2 (summer) & Analysis 2 (summer) \\
\hline $\mathrm{NO}_{2}, \mathrm{ppb}$ & $0.0434 \pm 0.01 \mathrm{I} 4, P<0.000 \mathrm{I}$ & $0.0160 \pm 0.0163, P>0.05$ & $0.0049 \pm 0.005 \mathrm{I}, P>0.05$ \\
\hline \multirow[t]{2}{*}{ Smoking } & $0.0410 \pm 0.0167, P<0.01$ & $0.0987 \pm 0.0235, P<0.000 I$ & $0.0306 \pm 0.0067, P<0.0001$ \\
\hline & Analysis 3 (winter) & Analysis 3 (winter) & Analysis 3 (winter) \\
\hline $\mathrm{NO}_{2}$, ppb & $0.0135 \pm 0.0149, P>0.05$ & $0.0224 \pm 0.0196, P>0.05$ & $-0.01101 \pm 0.0145, P>0.05$ \\
\hline \multirow{2}{*}{ Smoking } & $0.062 I \pm 0.0203, P<0.005$ & $0.0352 \pm 0.0263, P>0.05$ & $0.059 I \pm 0.0199, P<0.005$ \\
\hline & Analysis 4 (underlying) & Analysis 4 (underlying) & Analysis 4 (underlying) \\
\hline $\mathrm{NO}_{2}$, ppb & $0.0024 \pm 0.0072, P>0.05$ & $0.0385 \pm 0.0133, P<0.005$ & $0.0098 \pm 0.01 \mid 4, P>0.05$ \\
\hline \multirow[t]{2}{*}{ Smoking } & $0.0590 \pm 0.0104, P<0.0001$ & $0.0477 \pm 0.0204, P<0.05$ & $0.0986 \pm 0.0171, P<0.0001$ \\
\hline & Analysis I (ICD-9/I0) & Analysis I (ICD-9/I0) & Analysis I (ICD-9//0) \\
\hline CO, ppb & $0.0004 \pm 0.000 \mathrm{I}, P<0.000 \mathrm{I}$ & $0.0002 \pm 0.0001, P>0.05$ & $0.0002 \pm 0.0001, P<0.05$ \\
\hline \multirow[t]{2}{*}{ Smoking } & $0.0299 \pm 0.0084, P<0.00 \mathrm{I}$ & $0.0342 \pm 0.0120, P<0.01$ & $0.0386 \pm 0.0073, P<0.000 I$ \\
\hline & Analysis 2 (summer) & Analysis 2 (summer) & Analysis 2 (summer) \\
\hline $\mathrm{CO}, \mathrm{ppb}$ & $0.0013 \pm 0.0003, P<0.0001$ & $0.0017 \pm 0.0004, P<0.0001$ & $0.0002 \pm 0.000 \mathrm{I}, P>0.05$ \\
\hline \multirow[t]{2}{*}{ Smoking } & $0.0510 \pm 0.0149, P<0.001$ & $0.0766 \pm 0.0179, P<0.0001$ & $0.0298 \pm 0.0057, P<0.0001$ \\
\hline & Analysis 3 (winter) & Analysis 3 (winter) & Analysis 3 (winter) \\
\hline $\mathrm{CO}, \mathrm{ppb}$ & $0.0005 \pm 0.000 \mathrm{I}, P<0.00 \mathrm{I}$ & $0.0007 \pm 0.0002, P<0.0001$ & $0.000 I \pm 0.0002, P>0.05$ \\
\hline \multirow[t]{2}{*}{ Smoking } & $0.0267 \pm 0.0202, P>0.05$ & $-0.0173 \pm 0.0258, P>0.05$ & $0.0454 \pm 0.021 \mathrm{I}, P<0.05$ \\
\hline & Analysis 4 (underlying) & Analysis 4 (underlying) & Analysis 4 (underlying) \\
\hline CO, ppb & $0.000 \mathrm{I} \pm 0.000 \mathrm{I}, P>0.05$ & $0.0008 \pm 0.0002, P<0.0001$ & $0.0010 \pm 0.0001, P<0.0001$ \\
\hline \multirow[t]{2}{*}{ Smoking } & $0.050 \mathrm{I} \pm 0.0 \mathrm{I} 0 \mathrm{I}, P<0.000 \mathrm{I}$ & $0.0334 \pm 0.0194, P>0.05$ & $0.0352 \pm 0.0150, P<0.05$ \\
\hline & Analysis I (ICD-9/I0) & Analysis I (ICD-9//0) & Analysis I (ICD-9//0) \\
\hline $\mathrm{PM}_{2.5}, \mu \mathrm{g} / \mathrm{m}^{3}$ & $0.0155 \pm 0.0066, P<0.05$ & $0.0116 \pm 0.0083, P>0.05$ & $0.0044 \pm 0.0063, P>0.05$ \\
\hline \multirow[t]{2}{*}{ Smoking } & $0.04|4 \pm 0.0072, P<0.000|$ & $0.0329 \pm 0.0093, P<0.001$ & $0.0462 \pm 0.0067, P<0.000 I$ \\
\hline & Analysis 2 (summer) & Analysis 2 (summer) & Analysis 2 (summer) \\
\hline $\mathrm{PM}_{2.5}, \mu \mathrm{g} / \mathrm{m}^{3}$ & $0.0207 \pm 0.01 । 3, P>0.05$ & $0.0014 \pm 0.0105, P<0.05$ & $0.0016 \pm 0.0045, P>0.05$ \\
\hline Smoking & $0.0578 \pm 0.0152, P<0.000 \mathrm{I}$ & $0.0797 \pm 0.014 \mathrm{I}, P<0.000 \mathrm{I}$ & $0.0352 \pm 0.0060, P<0.0001$ \\
\hline
\end{tabular}

(Continued) 
Table SI (Continued)

\begin{tabular}{|c|c|c|c|}
\hline Potential health-impact factor & Emphysema & Asthma & Pneumonia \\
\hline & Analysis 3 (winter) & Analysis 3 (winter) & Analysis 3 (winter) \\
\hline $\mathrm{PM}_{2.5}, \mu \mathrm{g} / \mathrm{m}^{3}$ & $0.0224 \pm 0.0168, P>0.05$ & $0.0195 \pm 0.0186, P>0.05$ & $0.0039 \pm 0.0214, P>0.05$ \\
\hline \multirow[t]{2}{*}{ Smoking } & $0.0498 \pm 0.0154, P<0.001$ & $0.0049 \pm 0.0168, P>0.05$ & $0.0446 \pm 0.0193, P<0.05$ \\
\hline & Analysis 4 (underlying) & Analysis 4 (underlying) & Analysis 4 (underlying) \\
\hline $\mathrm{PM}_{2.5}, \mu \mathrm{g} / \mathrm{m}^{3}$ & $0.0030 \pm 0.0072, P>0.05$ & $0.0030 \pm 0.0137, P>0.05$ & $-0.0047 \pm 0.0101, P>0.05$ \\
\hline \multirow[t]{2}{*}{ Smoking } & $0.0560 \pm 0.0078, P<0.000 I$ & $0.0366 \pm 0.0154, P<0.05$ & $0.0667 \pm 0.0106, P<0.0001$ \\
\hline & Analysis I (ICD-9/I0) & Analysis I (ICD-9//0) & Analysis I (ICD-9//0) \\
\hline $\mathrm{PM}_{10}, \mu \mathrm{g} / \mathrm{m}^{3}$ & $0.0025 \pm 0.0039, P>0.05$ & $0.0125 \pm 0.0053, P<0.05$ & $-0.0012 \pm 0.0035, P>0.05$ \\
\hline \multirow[t]{2}{*}{ Smoking } & $0.052 I \pm 0.0072, P<0.000 I$ & $0.0395 \pm 0.0101, P<0.0001$ & $0.0508 \pm 0.0059, P<0.0001$ \\
\hline & Analysis 2 (summer) & Analysis 2 (summer) & Analysis 2 (summer) \\
\hline $\mathrm{PM}_{10}, \mu \mathrm{g} / \mathrm{m}^{3}$ & $0.0169 \pm 0.007 \mathrm{I}, P<0.05$ & $0.0243 \pm 0.0083, P<0.05$ & $-0.0029 \pm 0.0026, P>0.05$ \\
\hline \multirow[t]{2}{*}{ Smoking } & $0.07 \mid 4 \pm 0.0142, P<0.000 I$ & $0.1020 \pm 0.0176, P<0.0001$ & $0.0377 \pm 0.0050, P<0.0001$ \\
\hline & Analysis 3 (winter) & Analysis 3 (winter) & Analysis 3 (winter) \\
\hline $\mathrm{PM}_{10}, \mu \mathrm{g} / \mathrm{m}^{3}$ & $-0.0104 \pm 0.0143, P>0.05$ & $0.0407 \pm 0.0180, P<0.05$ & $-0.0135 \pm 0.0143, P>0.05$ \\
\hline \multirow[t]{2}{*}{ Smoking } & $0.0828 \pm 0.0170, P<0.0001$ & $0.0297 \pm 0.0213, P>0.05$ & $0.0569 \pm 0.0162, P<0.0005$ \\
\hline & Analysis 4 (underlying) & Analysis 4 (underlying) & Analysis 4 (underlying) \\
\hline $\mathrm{PM}_{10}, \mu \mathrm{g} / \mathrm{m}^{3}$ & $-0.0063 \pm 0.0047, P>0.05$ & $0.0256 \pm 0.0084, P<0.005$ & $0.0140 \pm 0.0074, P>0.05$ \\
\hline Smoking & $0.0662 \pm 0.0078, P<0.000 I$ & $0.0679 \pm 0.0163, P<0.0001$ & $0.0993 \pm 0.0133, P<0.0001$ \\
\hline
\end{tabular}

Notes: The following factors were tested: the potential effect of International Classification of Diseases (ICD) code changes (from ICD-9 to ICD-I0) (analysis I), the effects of air pollutants on mortality during the summer (analysis 2) and winter (analysis 3), and the association when only underlying causes of death contributed to the cause-specific death rates (analysis 4).

Abbreviation: PM, particulate matter.

\section{Publish your work in this journal}

The International Journal of COPD is an international, peer-reviewed journal of therapeutics and pharmacology focusing on concise rapid reporting of clinical studies and reviews in COPD. Special focus is given to the pathophysiological processes underlying the disease, intervention programs, patient focused education, and self management protocols.

\section{Dovepress}

This journal is indexed on PubMed Central, MedLine and CAS. The manuscript management system is completely online and includes a very quick and fair peer-review system, which is all easy to use. Visit http://www.dovepress.com/testimonials.php to read real quotes from published authors. 